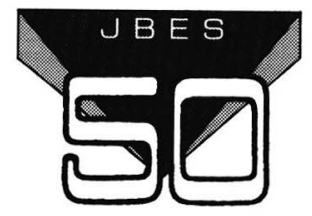

Invited Lecture

\title{
Gustav Killian and His Work-A Dawn of Endoscopy
}

\author{
Karl Hörmann, M.D. \\ Department of Otolaryngology, Head and Neck Surgery, University \\ Hospital of Mannheim, Germany
}

Key words : endoscopy, esophagoscopy, tracheobronchoscopy

\section{Gustav Killian - His Life}

Gustav Killian was born 1860 in Mainz in the Rhine valley, Germany. He attended medical school at the University of Strassburg. Among his teachers there have been so famous scientists such as Waldeyer, von Recklinghausen and Kussmaul, who invented gastroscopy in 1863. Killian later continued his studies in Freiburg and Berlin with Virchow, Wernicke, Henoch, von Langenbeck, Bergmann. 1884 Killian graduated from Heidelberg University and started his residency at the Municipal Hospital of Mannheim just 20 kilometers river downwards at the Neckar-Rhine-junction. During his military service in Freiburg he completed his doctoral thesis with the gynecologist Hegar. 1886 he started ENT-Training with Hartmann and Frenkel in Berlin. 1887 he settled as a general practioner in Mannheim again. 4 months later he was offered the chair of Otorhinolaryngology at Freiburg University.

This manuscript was presented at the special meeting to celebrate the 50th anniversary of the Japan Broncho-esophagological Society, 5th November, 1998, Kobe, Japan.

Correspondence to: Prof. Karl Hörmann, M.D., Klinikum der Stadt Mannheim, HNO-Klinik, Theoder-Kutzer Ufer 1-3, D-68167 Mannheim, Germany.

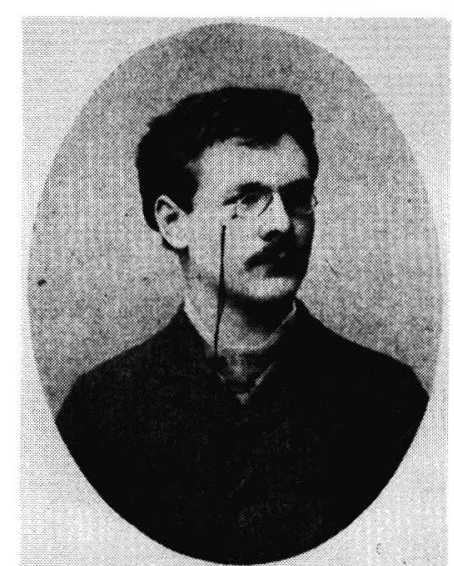

Fig. 1 Gustav Killian at the age of 27 in Mannheim.

This was the beginning of an extraordinary academical career and a rich scientific work.

When Killian took over in Freiburg, laryngology was part of the faculty of internal medicine. For procedures such as tracheotomies, patients had to be send to surgeons. He firstly followed his anatomical interests, studying intensively the anatomy and function of the muscles of the ear and also gave reports on his first innovative approach to endoscopic investigation of the upper airways using a mirror to perform the examination of the larynx. 1862 von Bruns started with indirect laryngoscopic procedures in Tübingen. First light source was the sun. Later, a candle light reflector for a perforated 4 head mirror 


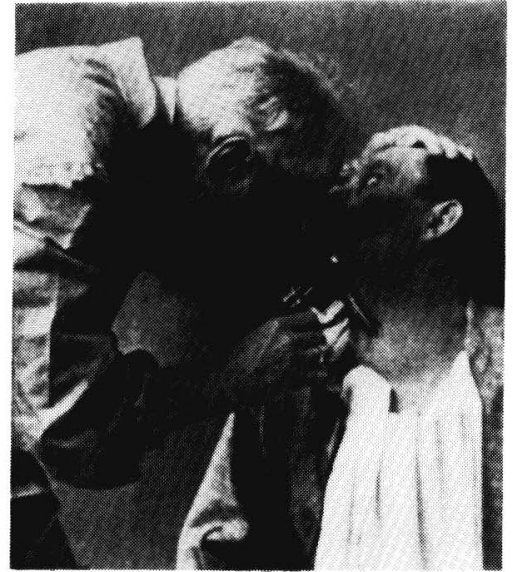

Fig. 2 Pieniacek 1886, introducing a rigid tube through a tracheotomy in the main bronchus.

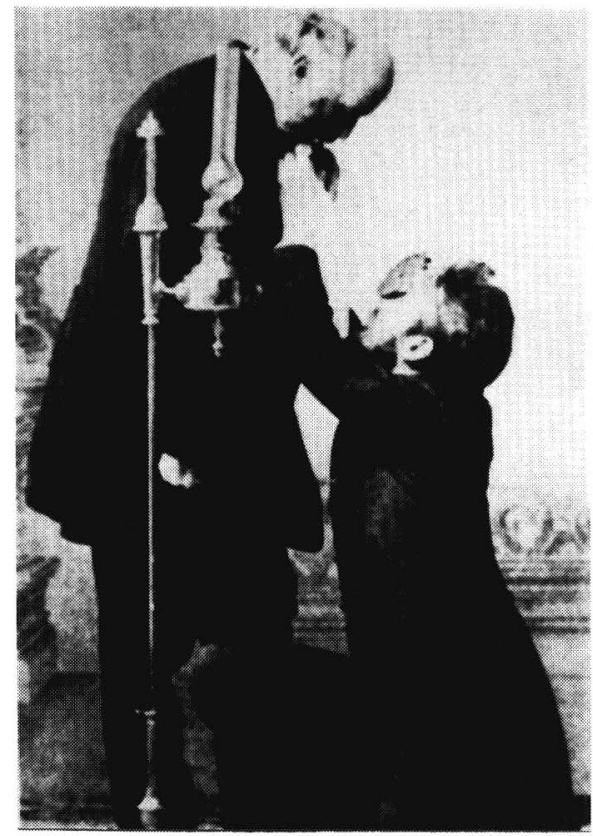

Fig. 3 Insight to the posterior laryngeal wall by the "Killians position."

was light source for the laryngeal mirror.

The bifurcation was demonstrated in the same way. Pieniacek 1886 in Krakow, at that time part of Austria, now Polen, first introduced a rigid tube through a tracheotomy in the main bronchus. In Freiburg, Killian improved the insight in the posterior

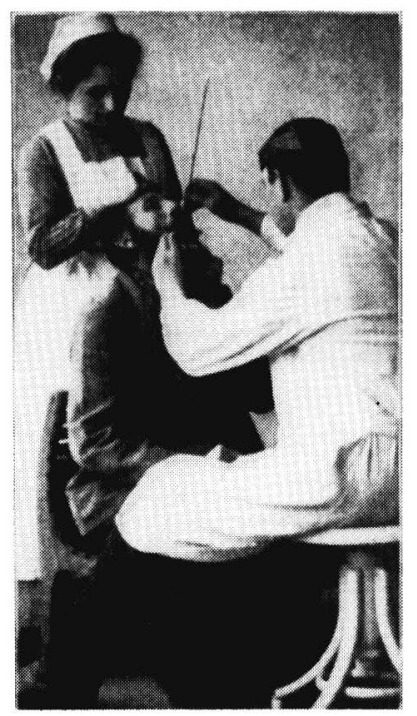

Fig. 4 Cocaine application into the larynx.

laryngeal wall by the "Killians position," which is demonstrated on Fig. 4.

In 1890, Alfred Kirstein, fascinated by the new method of endoscopy, enabled direct examination of the larynx. He proved that the trachea could be easily inspected once it was sufficiently anesthesized with cocaine. But seeing the pulsation of the aorta against the tracheal wall, he hesitated for fear of causing lethal bleeding by an accidental perforation. Learning about this, Killian realized the potential of this new method and began experimental work. Performing his first direct endoscopy via the larynx, he noticed the great flexibility of the trachea and could easily introduce the endoscope down to the lobar level.

In 1897 Killian removed the first foreign body through the trachea. In the same year, Killians coworker Kollofrath published the removal of a piece of bone from the right main bronchus in natural way using direct laryngoscopy. To understand the significance of this new technique, one has to be aware of the complications and clinical outcome of patients with aspiration of foreign bodies. In these days, this was a fatal disease with a 


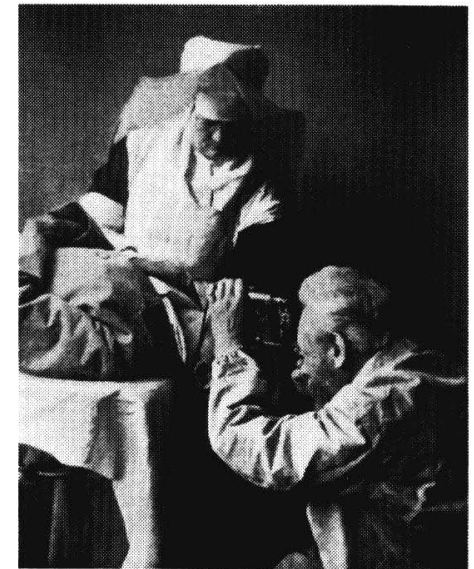

Fig. 51897 Killian doing direct bronchoscopy assisted by a Roman Catholic nurse.

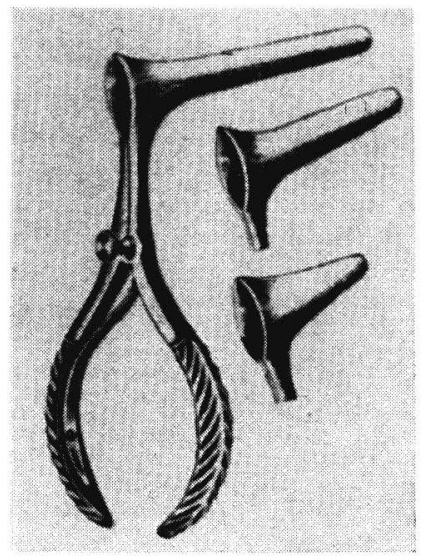

Fig. 6 Killian's speculum.

lethality of nearly $50 \%$. So at that time, it must have seemed a miracle that nearly all patients could be cured after the introduction of bronchoscopy. Special devices and instruments were developed for the removal of foreign bodies.

Although the development of bronchoscopy was Killian's main interest, he also developed a special speculum, demonstrated in Fig. 6 , the submucous septal resection and a radical procedure for the surgery of the frontal sinus, shown on Fig. 7. And he also did anatomical studies on Zenker's diverticulum. Killian was now very famous, teaching daily some visi-

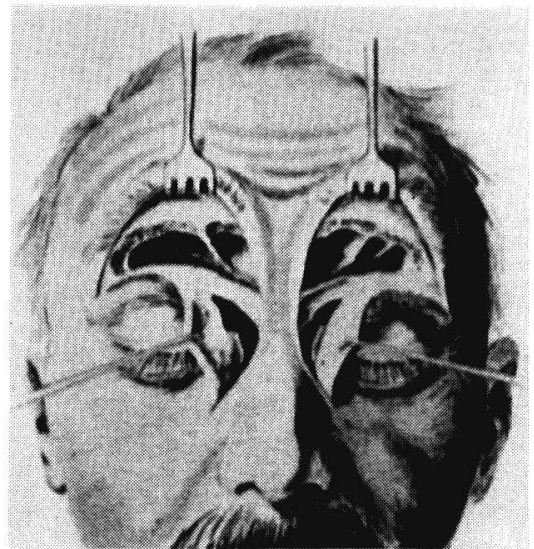

Fig. 7 Killian's radical procedure for the surgery of the frontal sinus.

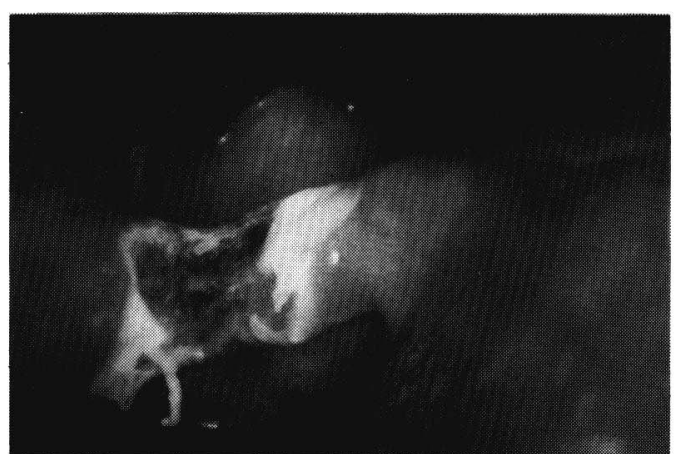

Fig. 8 Cricopharyngeal muscle of a Zenker's diverticulum dissected by $\mathrm{CO}_{2}$ laser endoscopically.

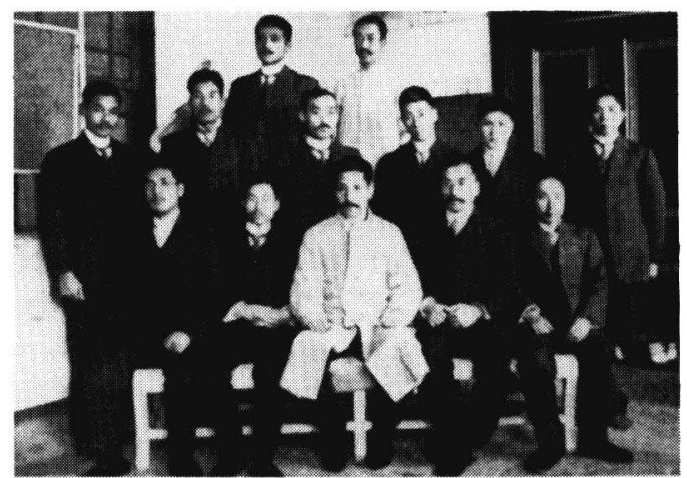

Fig. 9 Inokichi Kubo from Fukuoka, Japan, a coworker and pupil of Killian, surrounded by his residents. 


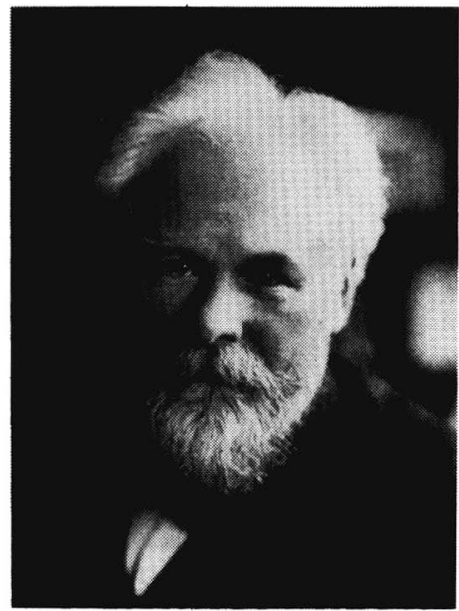

Fig. 10 The last photograph of Killian, 1920.

tors from all over the world how to perform bronchoscopy.

So in 1907 he was the first honory member of the society of American Oto-RhinoLaryngology. 1911 he suceeded Fraenkel at the chair in Berlin. He improved the suspense laryngoscopy now connected with the names of Kleinsasser, Weerda and Steiner. During first world war he studied injuries of the larynx and how to treat. 1920 he died from gastric cancer, but his ideas have spread all over the world and his enthusiasm had infected many rhinolaryngologists.

\section{A Dawn of Endoscopy}

The work of Gustav Killian has encouraged many endoscopists in the development of new techniques. He had set up a school of laryngologists, and his pupils dominated the field of German laryngology and bronchology for years. Many instruments for performing these new techniques were developed according to their ideas or even by their own hands.

Today, endoscopic resection of laryngeal tumors is one of the important concepts of therapy. The advantages of laser resection include minimal bleeding, precise control of resection and the absence of postoperative

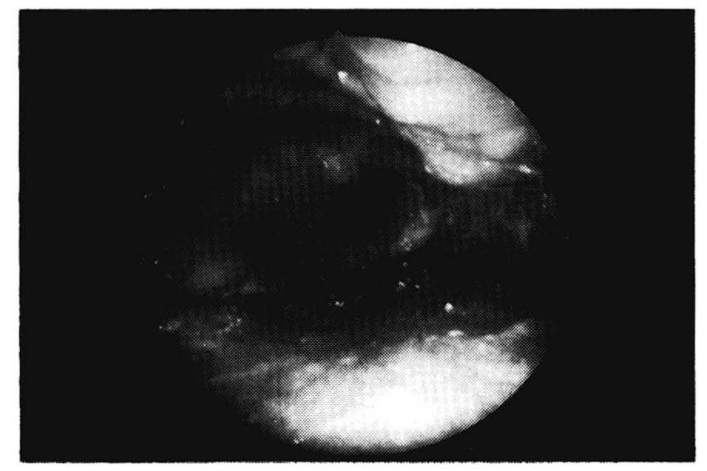

Fig. 11 Extended carcinoma of the hypopharynx and the larynx after transoral $\mathrm{CO}_{2}$ laser resection.

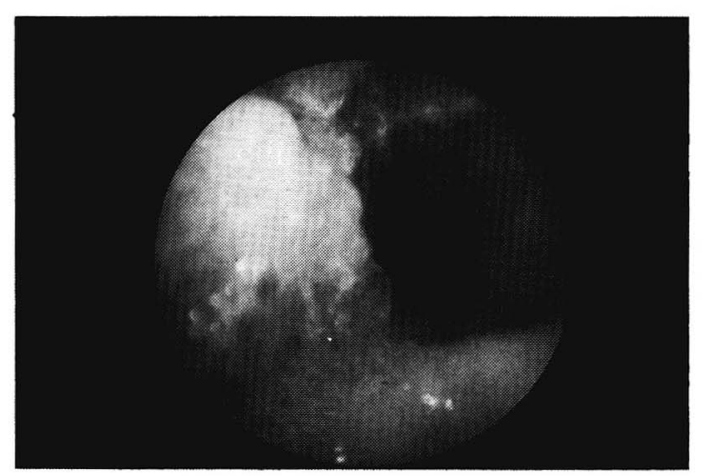

Fig. 12 Endoscopic view of a juvenile papillomatosis of the trachea.

edema. My coworkers and me published a prospective study on treatment of benign lesions of the vocal cord-conventioal microsurgery vs. $\mathrm{CO}_{2}$-lasersurgery. Another prospective study on organ preservation by transoral laser surgery and irradiation of $\mathrm{T} 3 / \mathrm{T} 4$ squamous cell carcinoma of the upper aerodigestive tract vs. radiochemotherapy vs. radical surgery/irradiation is nearly finished.

The Argon Plasma coagulation (APC) is a high frequency electrosurgical technique which our group adapted to the oto-rhinolaryngology. It is used today for a broad range of endoscopic indications. In 1996, we were the first to apply APC in otolaryngology for the treatment of juvenile papillomatosis. The good results have encouraged us to look for other indications in otolaryngology. 


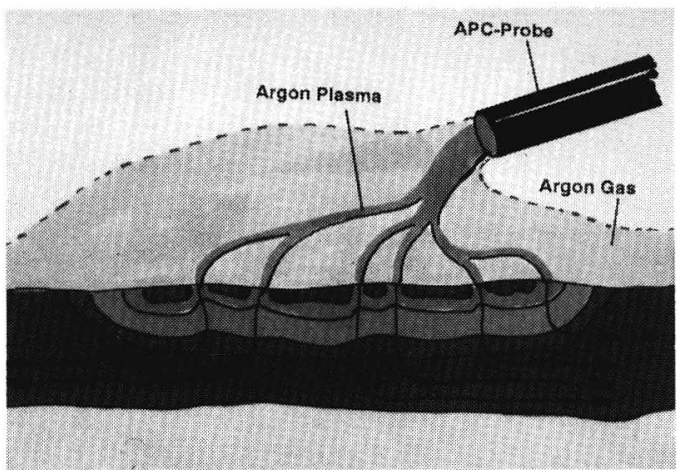

Fig. 13 Argon Plasma Coagulation (APC) applicator tip.

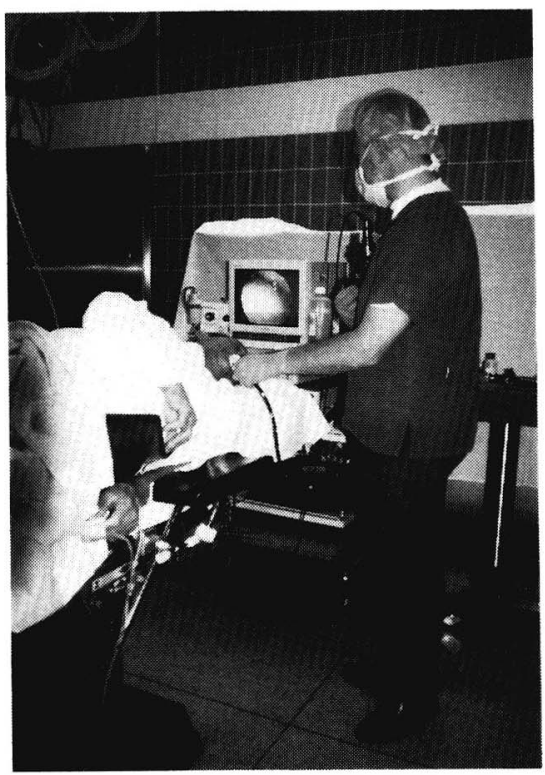

Fig. 14 Flexible esophagoscopy in presumed CUP-syndrome panendoscopy.

Regarding our preliminary results, APC offers an innovative, highly promising method of devitalizing tissue or to control superficial hemorrhages. Since Ikeda invented the first flexible endoscopy in 1964, there are strict indications for rigid endoscopy. Panendoscopy has become an important procedure for the diagnosis of head and neck cancer. Panendoscopy is performed in flexible technique in all our presumed cancer cases, especially in CUP-syndrome. In local anesthesia this outpatient procedure is highly effective and has an excellent cost-benefitrelation.

The "Working Group for Endoscopy of the German Otorhinolaryngological Society," headed by me, published guidelines how to perform tracheobronchoscopy or oesophagoscopy depending on different indications. This was done in close collaboration with endoscopic surgeons, pulmonologists and gastroenterologists. In conclusion the answer is :

\section{"seldom or not rigid or flexible but rigid and flexible."}

Rigid and flexible endoscopes are complementary, each with specific advantages in different situations.

The selection of instruments is determined by following criterias: the individual characteristics of the patient, the specific indication for endoscopy, and the experience of the endoscopist. The well-trained endoscopist is accomplished in the use of both and is not limited by prejudice. The specific instrument that is preferable for the particular patients and technical problem in selected. It is to the patient's advantage if both types of endoscopes are available. The procedure with the highest benefit to risk ratio can be employed for the individual case.

Acknowledgement: The author wants to thank Prof. Dr. med. H. Becker from the Department of Internal Medicine and Endoscopy, Thoraxclinic Heidelberg for his help in preparing this work.

\section{REFERENCES}

1) Bergler, W., Riedel, F., Baker-Schreyer, A., et al. : The Argon Plasma Coagulation in the treatment of hemorrhagic teleangiectasia. Laryngoscope, (in press).

2 ) Bergler, W., Riedel, F., Götte, K., et al. : Treatment of juvenile laryngeal papillomatosis with argon plasma coagulation. DMW, 19: 1105-1108, 1997 (in Japanese).

3 ) Bergler, W., Hönig, M., Götte, K., et al. : Treatment of recurrent respiratory papil- 
lomatosis with argon plasma coagulation. J. Laryngol. Otol., $111: 381-384,1997$.

4) Hönig, M., Taake, S., Baker-Schreyer, A., et al. : The Use of KTP laser in head and neck surgery. HNO, 46:452, 1998.

5 ) Hörmann, K., Baker-Schreyer, A., Keilmann, A., et al. : Functional results after $\mathrm{CO}_{2}$ laser surgery versus conventional phonosurgery. J. Laryngol. Otol., (in press).

6 ) Hörmann, K., Baker-Schreyer, A., Sadick, H., et al. : Minimal invasive transoral endoscopic laser surgery of advanced head and neck tumors. Endoskopie heute, 1:46(12), 1998.

7 ) Hörmann, K., Baker-Schreyer, A., Sadick, H., et al. : Onkologische Ergebnisse organerhaltender Laserchirurgie und adjuvanter Radiotherapie bei fortgeschrittenem (T3/T4) Larynxkarzinom. HNO, 46:467, 1998.

8 ) Hörmann, K., and Riedel, F. : Posttreatment of endonasal sinus surgery. HNO, (in press).

9 ) Hörmann, K., and Schmidt, H. : Flexible endoscopy in otolaryngology. HNO, $46: 654^{-}$ 659, 1998.

10) Hörmann, K.: Oesophagoscopy with the rigid tube. HNO, 45: 475, 1997.

11) Hörmann, K. : Tracheobronchoskopie sowie Mediastinoskopie. In : Oto-RhinoLaryngologie in Klinik und Praxis, Naumann, H.H., Helms, J., Herberhold, C., Kastenbauer, E. (Hrsg.), Georg Thieme Verlag Stuttgart, New York, Band 3 Hals, pp. 438-446, 1994.

12) Hörmann, K. : Neoadjuvante Therapiekonzepte: Neoadjuvante Chemotherapie beim Oropharynxkarzinom-Verbesserung der Prognose. Onkologie, 19: 81-93, 1996.

13) Hörmann, K. : Panendoscopy in presumed
CUP-syndrome. Br. J. Cancer, 77 (Suppl.1) : 1.1, 1998.

14) Keilmann, A., Nett, S., and Hörmann, K. : Auswirkungen der operativen Therapie des obstruktiven Schlafapnoesyndroms auf Schlucken und Sprachklang. Laryngol. Rhinol. Otol., 74: 555-558, 1995.

15) Keilmann, A., Bergler, W., Artzt, M., et al. : Vocal function following laser and conventional surgery of small malignant vocal cord tumours. J. Laryngol. Otol., 110 : 1138-1141, 1996.

16) Killian, G. : Über direkte Bronchoskopie. Münch Med. Wochenschr., 27 : 844-847, 1898.

17) Killian, G. : Zur Geschichte der Endoskopie von der ältesten Zeit bis Bozzini. Arch. Laryngol., XXIX : 247-393, 1915.

18) Killian, G. : Die submuköse Fensterresektion der Nasenscheidewand. Arch. Laryngol., 16 (3) : 203, 1904.

19) Killian, G. : Die Killiansche Radikaloperation chronischer Stirnhöhlenvereiterungen. Arch. Laryngol., 13:1, 1902.

20) Killian, G.: The mouth of the esophagus. Laryngoscope, June, 1907.

21) Kluge, F. : Adolf Kussmaul, Hippokrates Verlag, Stuttgart, 1985.

22) Schmidt, H., Hörmann, K., Stasche, N., et al. : Tracheobronchoskopie und Ösophaguskopie in der Hals-Nasen-Ohrenheilkunde. Eine Standortbestimmung. HNO, 46:643650, 1998.

23) Schmidt, H., Stasche, N., and Hörmann,K. : Guidelines-Oesophagoscopy, HNO, 46:651652, 1998.

24) Schmidt, H., Stasche, N., and Hörmann,K. : Guidelines - Tracheobronchoscopy. HNO, 46:652-653, 1998. 